\title{
IMPLEMENTASI METODE GREY VERHULST UNTUK MENDUKUNG KEBIJAKAN DALAM MENGANTISIPASI MAHASISWA DROPOUT
}

\author{
The Application of the Gray Verhulst Method to Support Policies in Anticipating \\ Students Dropping Out of School \\ Achmad Fitro*1, Rudianto ${ }^{2}$, Heru Prasetyo ${ }^{3}$ \\ ${ }^{1,2,3}$ Teknologi Komputer, Politeknik NSC Surabaya \\ e-mail:*2afi.subarjo@gmail.com, ${ }^{2}$ rudiantomcs@gmail.com, ${ }^{3}$ heru@nscpolteksby.ac.id
}

\begin{abstract}
Abstrak
Mahasiswa dropout merupakan masalah kompleks bagi setiap perguruan tinggi swasta seperti Politeknik NSC Surabaya, mahasiswa dropout dapat mengakibatkan berkurangnya kepercayaan masyarakat terhadap kualitas kampus. Politeknik NSC Surabaya terus berbenah dalam melakukan perbaikan kualitas baik segi pelayanan, jangkauan pembayaran, kualitas belajar mengajar, fasilitas yang dan memprediksi apapun yang besar kemungkinan membuat mahasiswa untuk putus study (drop out) salah satunya adalah memprediksi jumlah drop out terlebih dahulu. Grey Verhulst merupakan metode yang meningkatkan simulasi presisi dalam memprediksi berdasarkan data-data sebelumnya dan dapat digunakan untuk 1-4 langkah ke depan dengan akurat. Dengan menggunakan grey Verhulst, Politeknik NSC Surabaya mendapat hasil bahwa mahasiswa dropout terus meningkat di setiap tahunnya. Dengan begitu, hasil tersebut merupakan alert bagi Politeknik NSC Surabaya untuk segera merumuskan strategi dalam mengantisipasi mahasiswa dropout.
\end{abstract}

Kata kunci-Grey Verhulst, Drop Out, Prediksi, Grey model

\begin{abstract}
Dropout students are a complex problem for every private university such as the Polytechnic NSC Surabaya, dropout students can lead to reduced public confidence in the quality of the campus. Polytechnic NSC Surabaya continues to improve in improving the quality of service, payment range, quality of teaching and learning, facilities and predicting anything that is likely to make students drop out, one of which is predicting the number of drop outs first. Gray Verhulst is a method that improves simulation precision in predicting based on previous data and can be used for 1-4 steps ahead with accuracy. By using gray Verhulst, Polytechnic NSC Surabaya got the result that dropout students continued to increase every year. That way, these results are an alert for the Polytechnic NSC Surabaya to immediately formulate strategies in anticipating dropout students.
\end{abstract}

Keywords-3-5 Grey Verhulst, Drop Out, Prediction, Grey Model.

\section{PENDAHULUAN}

Perguruan tinggi merupakan salah satu tempat yang menyelenggarakan pendidikan akademik bagi mahasiswa yang berharap dapat menyelenggarakan pendidikan berkualitas untuk menghasilkan sumber daya manusia yang berkualitas di bidang pengetahuan, bermoral, dan dapat berdaya saing di dunia kerja. Perguruan tinggi di Indonesia saat ini memiliki jumlah yang sangat banyak, baik bidang vokasi maupun akademis. Sehingga pemerintah mengevaluasi perguruan tinggi mana yang layak menjadi pilihan mahasiswa dan mana yang tidak layak dengan mengeluarkan surat keputusan tentang persyaratan-persyaratan seperti rasio dosen, luas bangunan, pendidikan dosen, ruang dosen dsb. Akan tetapi, banyaknya mahasiswa dalam

Informasi Artikel:

Submitted: Oktober 2021, Accepted: November 2021, Published: November 2021

ISSN: 2685-4902 (media online), Website: http://jurnal.umus.ac.id/index.php/intech 
perguruan tinggi terkadang hanya dilihat sebagai kesuksesan atau keunggulan yang bagus dalam mendidik, sebaliknya kegagalan atau rendahnya kualitas mahasiswa sering dilihat sebagai ketidakmampuan perguruan tinggi dalam membina mahasiswa seperti halnya banyaknya mahasiswa putus kuliah (drop out).

Tingginya tingkat kegagalan atau mahasiswa dropout dapat merugikan bagi mahasiswa maupun perguruan tinggi tersebut . Oleh karna itu, perguruan tinggi memerlukan prediksi tentang jumlah mahasiswa baru untuk memenuhi persyaratan negara dan jumlah mahasiswa dropout, sehingga perguruan tinggi dapat mempersiapkan kebutuhan perguruan tinggi dan meminimalisir mahasiswa dropout dengan kebijakan yang mengarahkan dan mencegah mahasiswa dari dropout [1].

Banyak peneliti dalam menggunakan metode prediksi seperti Data Mining dengan algoritma ID3, C4.5 dan CART [2], Artificial Neural Network [3], Kualitatif [4], Grey Model [5] dan Grey Verhulst [6].

ANN memiliki kelebihan prediksi yang dimana bisa memasukkan faktor-faktor eksternal yang menurutnya akan mempengaruhi hasil prediksi meskipun tidak linear, akan tetapi ANN memiliki kekurangan yang membutuhkan data yang sangat besar [7]. Grey Model memiliki keunggulan tidak memerlukan data yang besar, menawarkan operasi yang mudah dan dapat menggunakan data acak untuk memberikan prediksi yang akurat. bahkan dalam penelitian [8] (Grey model hanya membutuhkan satu variable dalam memprediksi harga emas). Tetapi grey model memiliki kekurangan dalam adaptasi perubahan data [9]. Dengan begitu grey model ini sangat populer digunakan dalam memprediksi sesuatu pada saat ini. Sehingga banyak peneliti yang mengembangkan model ini untuk mengantisipasi kelemahan model tersebut, seperti Selfadapting Intellegent Grey Model IGM [10], Partical swom optimization Grey Model [11] dan Grey Verhulst Model [12] yang menurutnya adalah model grey yang dapat menunjukan akurasi terbaik dan ketahanan dalam perubahan kecepatan yang mendadak.

Berdasarkan latar belakang yang telah dijelaskan di atas, peneliti akan membuat sistem informasi yang mengimplementasikan metode grey verhulst dalam memprediksi jumlah pendaftaran mahasiswa baru dan mahasiswa dropout.

\section{Penelitian Terdahulu}

\section{METODE PENELITIAN}

Penelitian ini dapat dilaksanakan berdasarkan penelitian-penelitian sebelumnya yang mendukung dalam menghasilkan prediksi yang akurat dan perbaikan-perbaikan algoritma sehingga peneliti dapat merancang apa yang akan di teliti. Adapun penelitian terdahulu yang akan di tampilkan pada tabel di bawah ini.

Tabel 1. Penelitian sebelumnya

\begin{tabular}{|c|c|c|c|}
\hline $\begin{array}{l}\text { Penulis, } \\
\text { Tahun }\end{array}$ & Pembahasan & Metode & Hasil \\
\hline $\begin{array}{l}\text { (Askari } \\
\text { Askari, 2011) }\end{array}$ & Prediksi harga emas & $\begin{array}{l}\text { Grey } \\
\text { Model }\end{array}$ & $\begin{array}{l}\text { Model grey memiliki kinerja lebih baik } \\
\text { dalam model peramalan/prediksi }\end{array}$ \\
\hline $\begin{array}{l}\text { (Yi-Zhang, } \\
\text { 2012) }\end{array}$ & Perbaikan grey verhulst & $\begin{array}{l}\text { Grey } \\
\text { verhulst }\end{array}$ & $\begin{array}{l}\text { Meningkatkan simulasi presisi dan } \\
\text { memperluas ruang lingkup penerapan } \\
\text { model }\end{array}$ \\
\hline$(\mathrm{Ou}, 2012)$ & Peramalan hasil pertanian & $\begin{array}{l}\text { Grey } \\
\text { model }\end{array}$ & $\begin{array}{l}\text { Grey model tidak memerlukan jumlah } \\
\text { data besar untuk memberikan akurasi } \\
\text { yang tinggi dalam jangka pendek }\end{array}$ \\
\hline (Evans, 2014) & Memprediksi intensitas baja & $\begin{array}{l}\text { Grey } \\
\text { Verhulst } \\
\text { Model }\end{array}$ & $\begin{array}{l}\text { Grey verhulst mampu memprediksi } 1-4 \\
\text { langkah kedepan dengan akurat dan } \\
\text { masuk akal sehingga sangat }\end{array}$ \\
\hline
\end{tabular}




\begin{tabular}{lclll}
\hline $\begin{array}{l}\text { Penulis, } \\
\text { Tahun }\end{array}$ & Pembahasan & Metode & Hasil & \\
& & $\begin{array}{l}\text { memungkinkan } \\
\text { jangka panjang. }\end{array}$ & dalam & memprediksi
\end{tabular}

\begin{tabular}{|c|c|c|c|}
\hline $\begin{array}{l}\text { (Bezuglov \& } \\
\text { Comert, } \\
\text { 2016) }\end{array}$ & $\begin{array}{l}\text { Membandingkan grey model } \\
\text { dengan model time series yang } \\
\text { lainnya pada kecepatan lalu } \\
\text { lintas. }\end{array}$ & $\begin{array}{l}\text { Grey } \\
\text { Model dan } \\
\text { grey } \\
\text { verhulst } \\
\text { model }\end{array}$ & $\begin{array}{l}\text { Model grey model lebih akurat } \\
\text { dalam prediksi parameter lalu lintas } \\
\text { jangka pendek. } \\
\text { Grey verhulst menunjukkan akurasi } \\
\text { terbaik dan ketahanan perubahan } \\
\text { kecepatan yang mendadak } \\
\text { dibandingkan EFGM }\end{array}$ \\
\hline
\end{tabular}

\section{Teori Pendukung Penelitian \\ Prediksi}

Prediksi adalah suatu masalah yang diproses secara sistematis tentang menentukan nilai masa depan berdasarkan dari kumpulan data masa lalu dan saat ini. Prediksi itu sendiri tidak harus mendapatkan hasil yang pasti, melainkan dengan prediksi kita dapat mengetahui kemungkinan besar yang akan terjadi nantinya.

\section{Teknik Prediksi}

Berdasarkan teknik yang digunakan dalam memprediski maka teknik prediksi dapat dikategorikan menjadi dua macam,yaitu :

\section{Prediksi Kualitatif}

Prediksi kualitatif merupakan prediksi yang ditentukan berdasarkan pemikiran yang bersifat opini, pengetahuan dan pengalaman dari penyusunnya, dimana data yang digunakan tidak cukup maupun kurang dipercaya.

\section{Prediksi Kuantitatif}

Prediksi kuantitatif merupkaan prediksi yang berdasarkan atas data kuantitatif masa lalu dan dibuat dalam bentuk angka. Hasil prediksi yang dibuat sangat tergantung pada metode yang digunakan dalam prediksi tersebut. Dengan metode yang berbeda akan memperoleh hasil yang berbeda pula, sehingga baik tidaknya metode yang digunakan dapat ditentukan dari perbedaan atau penyimpangan antara hasil prediksi dengan kenyataan yang terjadi.

\section{Teori Grey System}

Teori grey sistem adalah teori yang kurang informasi atau hanya memiliki sebagian parameter yang diketahui. Teori ini memiliki tujuan untuk menjembatani kesenjangan antara ilmu social dan alam, sehingga dapat dikatakan bahwa terori grey sistem ini merupakan ilmu yang dapat diterapkan dalam memecahkan masalah di berbagai bidang seperti prediksi harga emas dan prediksi pengguna internet di Taiwan [13].

Grey sistem adalah nama yang dipilih berdasarkan warna dari subjek yang sedang diteliti. Dimana grey system terdapat pada tengah-tengah antara black dan white, black adalah kata untuk menujukkan informasi yang tidak diketahui dan white adalah kata untuk menunjukkan informasi yang sudah diketahui. Dengan berdasarkan warna tersebut grey system adalah kata untuk menunjukkan informasi yang dapat diketahui dan tidak dapat diketahui.

\section{Grey Generating}

Dalam proses parameter grey system dibutuhkan sebuah tehnik yang merubah data mentah yang tidak monoton atau random menjadi rangkaian data yang teratur yaitu grey generating. Adapun teknik tersebut memiliki 2 cara yaitu.

Accumulated Generating Operation (AGO) 
Misal data sebenarnya adalah $\mathrm{X}^{(0)}$ menunjukkan urutan waktu :

$$
X^{(0)}=\left(x^{(0)}(1), x^{(0)}(2), \ldots . ., x^{(0)}(n)\right), \quad n \geq 4
$$

Dengan $\mathrm{X}^{(0)}$ adalah barisan non-negatif dan $\mathrm{n}$ adalah sampel data yang yang harus lebih besar sama dengan empat agar bisa membentuk model grey. Selanjutnya urutan ini dijadikan Accumulating

Dengan contoh sebagai berikut, $X(0)=\{5,10,7,9\}$ maka $X(1)=\{5,15,22,31\}$, maka data asli dapat ditunjukkan pada gambar 1 dan data melalui proses AGO ditunjukkan pada gambar 2.

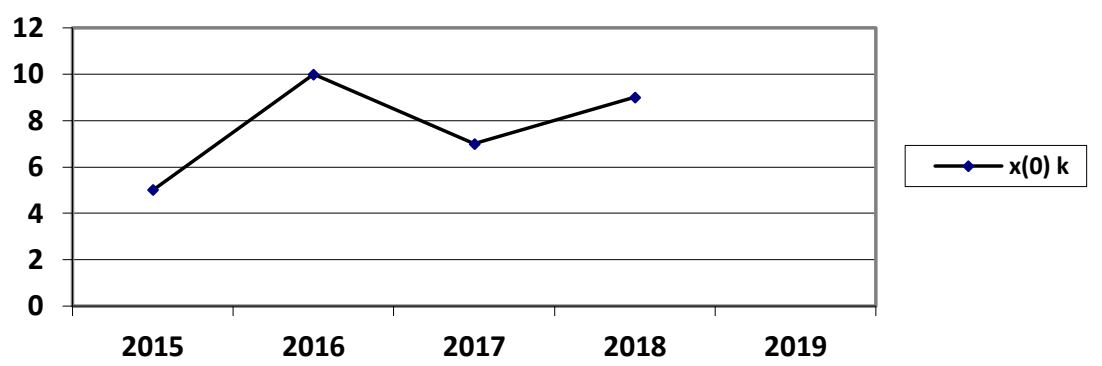

Gambar 1 Grafik data asli

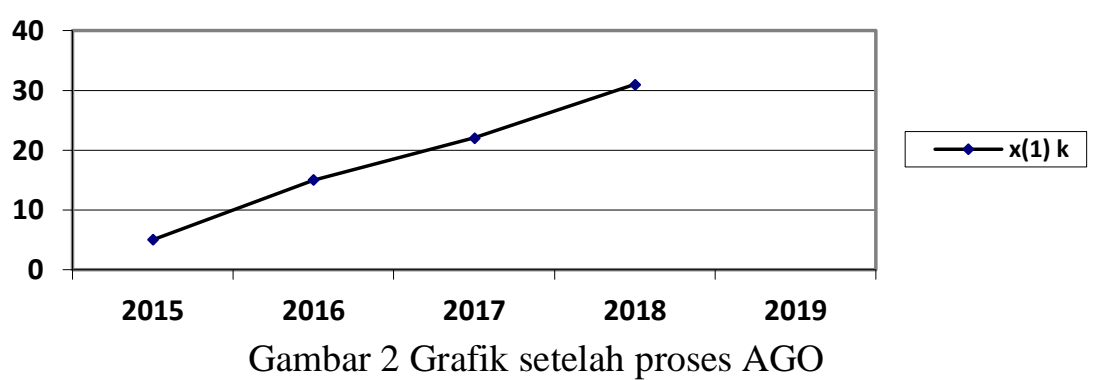

\section{Inverse Accumulated Generating Operation (IAGO)}

Teknik IAGO ini digunakan untuk mendapatkan nilai prediksi dari data asli yang telah melalui proses AGO. IAGO memiliki persamaan sebagai berikut :

$$
\begin{aligned}
x^{(1)}(k) & =\sum_{i=1}^{k} x^{(0)}(i) \\
& =\sum_{i=1}^{k-1} x^{(0)}(i)+x^{(0)}(k) \\
& =x^{(1)}(k-1)+x^{(0)}(k) \\
x^{(0)}(k) & =x^{(1)}(k)-x^{(1)}(k-1)
\end{aligned}
$$

\section{Grey Verhulst}

Grey verhulst pertama kali dikenalkan oleh pierre franois verhulst seorang ahli biologi dari jerman. Tujuan utama dari grey verhulst adalah untuk membatasi perkembangan proses dan efektif untuk menggambarkan beberapa peningkatan dalam proses. Model grey verhulst dinyatakan dengan persamaan differensial

$$
\frac{d x^{(1)}(t)}{d t}+a x^{(1)}(t)=b\left(x^{(1)}(t)\right)^{2}
$$

Persamaan differensi model grey verhulst adalah :

$$
\begin{gathered}
x^{(0)}(k)+a Z^{(1)}(k)=b\left(Z^{(1)}(k)\right)^{2}, \\
x^{(0)}(k)=-a Z^{(1)}(k)+b\left(Z^{(1)}(k)\right)^{2}
\end{gathered}
$$

Berbeda dengan model grey pada dasarnya yang menyusun data asli sebagai $\mathrm{X}^{(0)}$, akan tetapi di dalam model grey verhulst data asli digunakan sebagai data $\mathrm{X}^{(1)}$ dan data $\mathrm{X}^{(0)}$ didapat dari menghitung dengan persamaan (2)

Adapun langkah-langkah penerapan model grey verhulst dalam memprediksi adalah sebagai berikut :

a) Menyusun barisan data asli mahasiswa dropout berdasarkan tahun ajaran. 
b) Menghitung barisan data $\mathrm{X}^{(0)}$.

$$
x^{(1)}=\left(x^{(1)}(1), x^{(1)}(2), \ldots . ., x^{(1)}(n)\right)
$$

$$
x^{(0)}(k)=x^{(1)}(k)-x^{(1)}(k-1)
$$

c) Membentuk barisan rata-rata $Z^{(1)}$ yang didapat dari hitungan barisan $X^{(1)}$ dengan persamaan

$$
Z^{(1)}(k)=0.5 x^{(1)}(k)+0.5 x^{(1)}(k-1), k=2,3,4, \ldots, n \text {. }
$$

d) Menentukan kuadrat terkecil untuk mencari parameter $a$ dan $b$

$\alpha=(\mathrm{a}, \mathrm{b})^{\mathrm{T}}$ dengan persamaan

Maka kita akan mendapatkan persamaan matrik

$$
Y=\left\{\begin{array}{c}
x^{(0)}(2) \\
x^{(0)}(3) \\
\cdot \\
\cdot \\
x^{(0)}(n)
\end{array}\right\}, \quad B=\left\{\begin{array}{cc}
-z^{(1)}(2) & z^{(1)}(2)^{2} \\
-z^{(1)}(3) & z^{(1)}(3)^{2} \\
\cdot & \cdot \\
\cdot & \cdot \\
-z^{(1)}(n) & z^{(1)}(n)^{2}
\end{array}\right\}
$$

e) Menghitung solusi penyelesaian atau fungsi respon waktu dari persamaan diferensial Bernoulli.

$$
\hat{\chi}^{(1)}(k+1)=\frac{a x^{(1)}(1)}{b x^{(1)}(1)+\left(a-b x^{(1)}(1)\right) e^{a k}}
$$

\section{Keakuratan Prediksi}

Keakuratan dalam model prediksi ini yang pertama harus dilakukan adalah selisih dari nilai actual yang disebut dengan sisaan $\in(k)$ dan menghitung nilai relative percentage error (RPE) . Selanjutnya untuk menunjukkan keakuratan model dapat dilihat dari besarnya nilai average relative percentage error (ARPE). Berikut persamaan dalam mempredisksi keakuratan prediksi dan model

$$
\begin{aligned}
& \in(k)=x^{(0)}(k)-x_{p}^{(0)}(k) \\
& R P E(k)=\frac{|\epsilon(k)|}{x^{(0)}(k)} x 100 \% \\
& A R P E=\frac{1}{n-1} \sum_{k=2}^{n} \frac{|\in(k)|}{x^{(0)}(k)}
\end{aligned}
$$

\section{HASIL DAN PEMBAHASAN}

Dalam pembahasan ini, peneliti akan penjelasan terkait implementasi metode grey verhulst dalam memprediksi mahasiswa drop out pada Politeknik NSC Surabaya sehingga hasil prediksi dapat menjadi acuan dalam membuat strategi kebijakan peruguran tinggi jika mahasiswa drop out terus meningkat pada setiap tahunnya. Berikut data mahasiswa drop out yang akan disajikan dalam tabel 2 untuk digunakan dalam memprediksi.

Tabel 2. Mahasiswa drop out Politeknik NSC Surabaya

\begin{tabular}{c|cccc|c}
\hline TAHUN & $\begin{array}{c}\text { Teknik } \\
\text { Komputer }\end{array}$ & Perhotelan & Akuntansi & $\begin{array}{c}\text { Administrasi } \\
\text { Bisnis }\end{array}$ & TOTAL \\
\hline 2013 & 9 & 6 & 5 & 16 & 36 \\
2014 & 30 & 20 & 14 & 10 & 74 \\
2015 & 40 & 29 & 18 & 20 & 107 \\
2016 & 30 & 18 & 19 & 13 & 80 \\
2017 & 15 & 14 & 9 & 6 & 44 \\
2018 & 14 & 13 & 4 & 10 & 41 \\
2019 & 6 & 11 & 11 & 5 & 33 \\
2020 & 15 & 21 & 4 & 6 & 46 \\
\hline
\end{tabular}


Perhitungan Grey Verhulst

Perhitungan dalam metode grey verhulst memiliki enam langkah dalam memprediksi mahasiswa drop out. Berikut uraian langkah-langkah dengan menggunakan data tabel 2 :

1. Menyusun barisan data asli mahasiswa dropout berdasarkan tahun ajaran dengan menggunakan persamaan (5), menghitung barisan data $X^{(0)}$ dengan persamaan (6) dan memberntuk barisan rata-rata $Z^{(1)}$ yang didapat dari hitungan $\mathrm{X}^{(1)}$ dengan persamaan (7). Berikut hasil yang dapat disajikan pada tabel 3 .

Tabel 3. Hasil perhitungan data asli, data AGO dan barisan rata-rata

\begin{tabular}{cccc}
\hline Tahun & Data Asli & $\mathbf{X}^{(\mathbf{0})}$ & $\mathbf{Z}^{(\mathbf{1})}$ \\
\hline 2013 & 36 & 36 & 36 \\
2014 & 74 & 38 & 55 \\
2015 & 107 & 33 & 90.5 \\
2016 & 80 & -27 & 93.5 \\
2017 & 44 & -36 & 62 \\
2018 & 41 & -3 & 42.5 \\
2019 & 33 & -8 & 37 \\
2020 & 46 & 13 & 39.5 \\
\hline
\end{tabular}

2. Menentukan kuadrat terkecil untuk mencari parameter $a$ dan $b$.

$\alpha=(\mathrm{a}, \mathrm{b})^{\mathrm{T}}$ dengan persamaan $(8)$.

$B=\left|\begin{array}{ll}-55 & 3025 \\ -90.5 & 8190 \\ -93.5 & 8742 \\ -62 & 3844 \\ -42.5 & 1806 \\ -37 & 1369 \\ -39.5 & 1560\end{array}\right| \quad Y=\left|\begin{array}{l}38 \\ 33 \\ -27 \\ -36 \\ -3 \\ -8 \\ 13\end{array}\right|$

Selanjutnya akan dilakukan perhitungan matrik $\mathrm{B}^{\mathrm{t}} \mathrm{B}$ sebagai berikut.

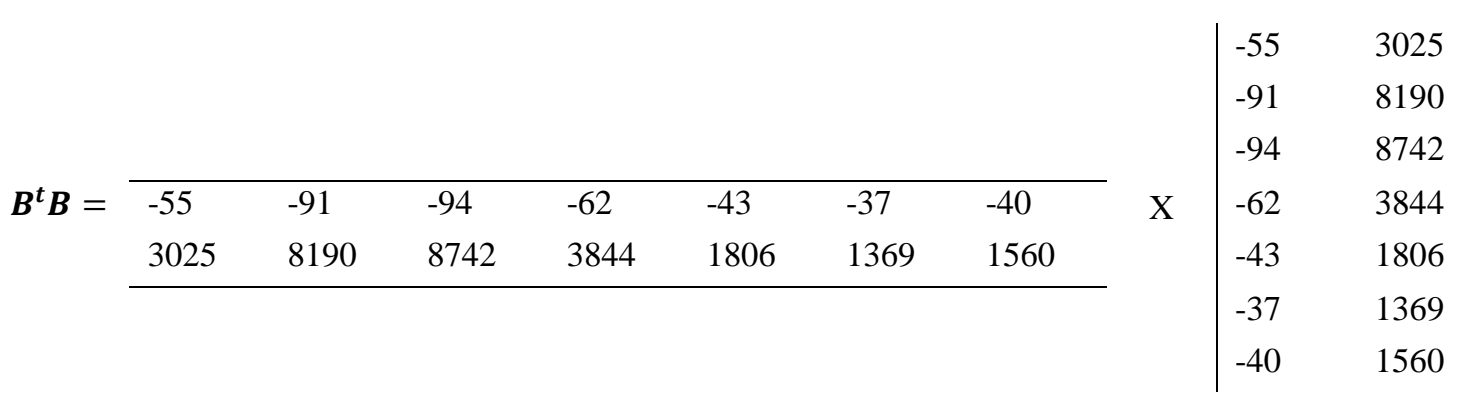

Setelah kita mendapatkan matrik $\mathrm{B}^{\mathrm{t}} \mathrm{B}$ dan $\mathrm{X}$. Langkah selanjutnya mendapatkan perhitungan matrix $\hat{a}=\left(B^{T} B\right)^{-1} B^{T} Y$ sebagai berikut.

$\mathrm{B}^{\mathrm{t}} \mathrm{B}=\left|\begin{array}{rr}28537 & -2152370 \\ -2152370 & 175005171\end{array}\right|,\left[\mathrm{B}^{\mathrm{t}} \mathrm{B}\right]^{-1}=\left|\begin{array}{ll}0.000484205 & 0.000005955 \\ 0.000005955 & 0.000000079\end{array}\right|$

Dan,

$$
B^{t} Y=\left|\begin{array}{rr}
28537 & -2152370 \\
-2152370 & 175005171
\end{array}\right|
$$


Dengan matrik yang sudah kita gunakan, maka kita sudah mendapatkan nilai $a$ dan $b$ yaitu : $a=-0.1109$ dan $b=0.0013$.

3. Menghitung solusi penyelesaian respon waktu dengan menggunakan persamaan (9).

$$
\begin{aligned}
\hat{x}^{(1)}(k+1) & =\frac{-0.1109(36.00)}{0.0013\left(36.00+(-0.1109(-0.0013)) e^{-0.1109}\right.} \\
& =\frac{-3.99}{-0.05+(-0.06) e^{-0.11}} \\
& =38.35
\end{aligned}
$$

Selanjutnya menghitung nilai prediksi berikut sebanyak data yang tersedia sehingga akan mendapatkan hasil seperti yang dijelaskan pada tabel 4.

Tabel 4. Perhitungan prediksi

\begin{tabular}{|lllllllll|l|}
\hline $\mathrm{X}_{\mathrm{p}}{ }^{(1)}(2)$ & $=$ & -3.99 & $/$ & -0.05 & + & -0.06 & 2.72 & -0.11 & 38.35 \\
$\mathrm{X}_{\mathrm{p}}{ }^{(1)}(3)$ & $=$ & -3.99 & $/$ & -0.05 & + & -0.06 & 2.72 & -0.22 & 40.74 \\
$\mathrm{X}_{\mathrm{p}}{ }^{(1)}(4)$ & $=$ & -3.99 & $/$ & -0.05 & + & -0.06 & 2.72 & -0.33 & 43.14 \\
$\mathrm{X}_{\mathrm{p}}{ }^{(1)}(5)$ & $=$ & -3.99 & $/$ & -0.05 & + & -0.06 & 2.72 & -0.44 & 45.54 \\
$\mathrm{X}_{\mathrm{p}}{ }^{(1)}(6)$ & $=$ & -3.99 & $/$ & -0.05 & + & -0.06 & 2.72 & -0.55 & 47.92 \\
$\mathrm{X}_{\mathrm{p}}{ }^{(1)}(7)$ & $=$ & -3.99 & $/$ & -0.05 & + & -0.06 & 2.72 & -0.67 & 50.28 \\
$\mathrm{X}_{\mathrm{p}}{ }^{(1)}(8)$ & $=$ & -3.99 & $/$ & -0.05 & + & -0.06 & 2.72 & -0.78 & 52.60 \\
& & -3.99 & $/$ & -0.05 & + & -0.06 & 2.72 & -0.89 & 54.86
\end{tabular}

Selanjutnya melakukan pemeriksaan keakuratan prediksi yang disajikan pada tabel 5 dengan menghitung nilai sisaan $\in(k)$ yang dihitung menggunakan persamaan (10) dan nilai RPE (k) dengan persamaan (11).

Tabel 5. Pemeriksaan keakuratan prediksi

\begin{tabular}{ccccc}
\hline $\mathbf{k}$ & Data Asli & $\begin{array}{c}\text { Data } \\
\text { Prediksi }\end{array}$ & Sisaan & $\boldsymbol{R P E}(\boldsymbol{k})$ \\
\hline 2 & 74 & 38 & 36 & 48 \\
3 & 107 & 41 & 66 & 62 \\
4 & 80 & 43 & 37 & 46 \\
5 & 44 & 46 & -2 & -3 \\
6 & 41 & 48 & -7 & -17 \\
7 & 33 & 50 & -17 & -52 \\
8 & 46 & 53 & -7 & -14 \\
9 & & 55 & & \\
\hline
\end{tabular}

Selanjutnya menghitung nilai ARPE dengan menggunakan persamaan (12),

$$
\begin{aligned}
\mathrm{ARPE} & =\frac{1}{7}(48+62+46+(-3)+(-17)+(-52)+(-14)) \% \\
& =9.87 \%
\end{aligned}
$$

Dengan begitu keakuratan dalam prediksi menggunakan metode grey verhulst mencapai $\mathbf{9 0 . 1 3} \%$.

\section{KESIMPULAN}

Dari hasil pembahasan, maka penulis dapat menyimpulkan bahwa metode grey verhulst cukup akurat dalam memprediksi dengan nilai prediksi diatas $90 \%$ dan implementasi metode ini menunjukkan bahwa mahasiswa drop out meningkat pada tahun berikutnya, sehingga dengan hasil ini penulis dapat memberikan alert kepada pihak perguruan tinggi untuk segera merumuskan strategi kebijakan dalam mengantisipasi mahasiswa drop out. 


\section{DAFTAR PUSTAKA}

[1]. Dekker, G. W., Pechenizkiy, M., \& Vleeshouwers, J. M. (2009). Predicting students drop out: A case study. EDM'09 - Educational Data Mining 2009: 2nd International Conference on Educational Data Mining, 41-50.

[2]. Pal, S. (2012). Mining Educational Data to Reduce Dropout Rates of Engineering Students. International Journal of Information Engineering and Electronic Business, 4(2). https://doi.org/10.5815/ijieeb.2012.02.01

[3]. Kurdthongmee, W. (2008). Colour classification of rubberwood boards for fingerjoint manufacturing using a SOM neural network and image processing. Computers and Electronics in Agriculture, 64(2). https://doi.org/10.1016/j.compag.2008.04.002.

[4]. Altan, A., \& Karasu, S. (2019). The effect of kernel values in support vector machine to forecasting performance of financial time series and cognitive decision making. The Journal of Cognitive Systems, 4(1).

[5]. Askari, M., \& Askari, H. (2011). Time Series Grey System Prediction-based Models: Gold Price Forecasting. Trends in Applied Sciences Research, 6(11). https://doi.org/10.3923/tasr.2011.1287.1292.

[6]. Evans, M. (2014). An alternative approach to estimating the parameters of a generalised Grey Verhulst model: An application to steel intensity of use in the UK. Expert Systems with Applications, 41(4 PART 1). https://doi.org/10.1016/j.eswa.2013.08.006.

[7]. Nguyen, H., Moayedi, H., Foong, L. K., Al Najjar, H. A. H., Jusoh, W. A. W., Rashid, A. S. A., \& Jamali, J. (2020). Optimizing ANN models with PSO for predicting short building seismic response. Engineering with Computers, 36(3). https://doi.org/10.1007/s00366019-00733-0.

[8]. Li, W., Zhao, X., \& Liu, S. (2020). Traffic accident prediction based on multivariable grey model. Information (Switzerland), 11(4). https://doi.org/10.3390/info11040184.

[9]. Ou, S. L. (2012). Forecasting agricultural output with an improved grey forecasting model based on the genetic algorithm. Computers and Electronics in Agriculture, 85. https://doi.org/10.1016/j.compag.2012.03.007.

[10]. Zeng, B., \& Li, C. (2016). Forecasting the natural gas demand in China using a self$\begin{array}{llll}\text { adapting intelligent grey } & 112 .\end{array}$ https://doi.org/10.1016/j.energy.2016.06.090.

[11]. Li, K., Liu, L., Zhai, J., Khoshgoftaar, T. M., \& Li, T. (2016). The improved grey model based on particle swarm optimization algorithm for time series prediction. Engineering Applications of Artificial Intelligence, 55, 285-291. https://doi.org/10.1016/J.ENGAPPAI.2016.07.005.

[12]. Bezuglov, A., \& Comert, G. (2016). Short-term freeway traffic parameter prediction: Application of grey system theory models. Expert Systems with Applications, 62, 284292. https://doi.org/10.1016/J.ESWA.2016.06.032.

[13]. Wang, X., Qi, L., Chen, C., Tang, J., \& Jiang, M. (2014). Grey System Theory based prediction for topic trend on Internet. Engineering Applications of Artificial Intelligence, 29, 191-200. https://doi.org/10.1016/J.ENGAPPAI.2013.12.005. 